\title{
Leadership and Task Shifting to Address the Challenges of Antimicrobial Resistance in South Africa
}

\author{
Kemesha Govender', Samridhi Sharma' ${ }^{1}$, William Jessee ${ }^{2}$, Kiran Nagaraju' ${ }^{1,3}$, \\ Noel J. Pearse ${ }^{4}$, Pratik Chhetri ${ }^{5}$, Elisa M. Bodenstab ${ }^{6}$, Pei Yu ${ }^{7}$, Sunitha C. Srinivas ${ }^{1 *}$ \\ 'Faculty of Pharmacy, Rhodes University, Grahamstown, South Africa; s.srinivas@ru.ac.za \\ ${ }^{2}$ Ambulatory Pharmacy Services, Cleveland Clinic Abu Dhabi, Abu Dhabi \\ ${ }^{3}$ Department of Pharmacy Practice, Visveswarapura Institute of Pharmaceutical Sciences, Bengaluru, India \\ ${ }^{4}$ Rhodes Business School, Rhodes University, Grahamstown, South Africa \\ ${ }^{5}$ LMIC Chapter Co-ordinator, UAEM and Executive Team member, YP-CDN \\ ${ }^{6}$ Department of Anthropology, Rhodes University, Grahamstown \\ ${ }^{7}$ College of Pharmacy, Jinan University, Guangzhou, China
}

\begin{abstract}
Antimicrobial resistance is a complex problem interconnected with many factors, such as overuse and misuse of antimicrobials across the world, especially in Low- and Middle-Income Countries (LMICs). To overcome this, the Global Action Plan requires commitment action in LMICs, aimed at education and health promotion to all. Demand for the Health Care Professionals (HCPs) in developed countries and exponential chances of earning had led to the shortage of HCPs in most countries and severe shortage in more than 50 LMICs. Community Health Workers (CHWs) are being recognised in many LMICs to deliver primary health care service with minimum training as an alternative solution to combat the situation, which can improve the cost-effectiveness of health care systems. These CHWs can reach large number of people in the community where the public sector provided health service is very minimal and private health care sector is unaffordable.
\end{abstract}

Keywords: Antimicrobial Agents, Antimicrobial Resistance, Community Health Workers, Leadership, Task Shifting, World Health Organisation, Youth Empowerment

\section{Introduction}

Antimicrobial therapeutics has revolutionized human health care worldwide, but their use and overuse have also led to an increasing prevalence of infectious microorganisms that are resistant to available forms of treatment. Antimicrobial Resistance (AMR) is rapidly becoming a major global health issue, and poses a threat to the health of the population, and to the financial sustainability of health care systems and broader economies ${ }^{1-3}$. The grave concerns AMR carries is the reason the World Health Organization (WHO) recently announced the formation of an Ad Hoc Interagency Coordination Group ${ }^{4}$. The newly elected WHO Director-General also considers AMR as one of the most complex global challenges under his leadership 5 .

Patients affected by AMR frequently develop complications which increase morbidity and mortality, as seen by the death toll, even in developed countries, which have more reliable systems to monitor these effects. AMR

${ }^{*}$ Author for correspondence 
is the cause of significant detrimental consequences on the health of individuals in both developed and developing countries in multiple ways like prolonged morbidity; increased hospital stays; increased likelihood of developing other comorbidities or complications; more intensive and expensive treatments; increased risk of adverse drug reactions; and higher mortality rates ${ }^{6,7}$. AMR is brought about by many factors, and a variety of sectors (industry, community, health systems, etc.) contribute to its burden. These contributing factors bear additional consequences which affect the entire society and economy.

\section{Discussion}

\subsection{Impact on Labour from Inadequate Development of Antimicrobials}

A combination of having less developed health systems, higher rates of infectious diseases, low-quality medicines (including those that are counterfeit and spurious), and improper use of antibiotics, among other factors, increases the burden of AMR in LMICs, such as South Africa $^{8}$. Between 1980 and 1999, 51 antibiotics were approved by the U.S. FDA, followed by a period of very slow development and approval of new antibiotics9. The concern with lacking development of new antibiotics is due to increasing rates of AMR, as many people will not be able to receive effective treatment. One of the commonly cited reasons for the lack of development of new antibiotics is largely due to the lack of profit for pharmaceutical companies. Pharmaceutical companies that manufacture medicines to treat the increasing demands of Non-Communicable Diseases (NCDs) are more profitable ${ }^{10,11}$.

In this context, it is most important to highlight that the Research and Development (R\&D) pipeline for new Antimicrobial Therapies (AMTs) is progressively drying up rather than being a proactive and progressive response to this global health challenge. The approval of novel AMTs has fallen many folds and consequently, the current AMT pipeline is very limited ${ }^{12-15}$. Investment in this area has become unattractive due to diminished returns on capital, principally driven by accelerating rates of AMR to new AMTs, and increased restrictions on their use. Innovative approaches are required to stimulate sufficient $\mathrm{R} \& \mathrm{D}$ activity. Delinking R\&D incentives from eventual sales of the product is crucial in fostering investment in this area. Curative treatment (rather than long term use seen in chronic diseases); limited/specified duration of antibiotic regimens; availability of generic antibiotics; rapid resistance resulting in shorter clinical lifespan and financial returns; bacterial mutation and horizontal gene transfer within and between species; regulatory hurdles; conflict of health policy (reducing use of antibiotics) versus industrial policy (increasing innovation) are all complex factors resulting in less innovation of antibiotics, thereby requiring a new business model ${ }^{16}$ as well as stronger alliance between stakeholders ${ }^{17}$ and strengthened international partnership ${ }^{18}$.

Since the 1950s, the development of pharmaceutical technology has relied on a profit model underpinned by market exclusivity. As per this model, pharmaceutical $\mathrm{R} \& \mathrm{D}$ is financed predominantly by private capital seeking a commensurate return, and is conducted by pharmaceutical companies. Return of Investment (ROI) is determined by two factors: the price of the medicine and the volume sold. Overall, this model has worked in delivering innovative therapies (including AMTs) that have improved human health and social progress. However, in seeking to maximise capital returns, AMTs were marketed aggressively, resulting in indiscriminate prescribing and distribution. This hastened the rate of resistance. Newer antimicrobials became obsolete sooner, extinguishing profits and making investment in this area unattractive ${ }^{19}$.

Increases in resistant infections have the potential to decrease the quality and quantity of the labour supply, as fewer individuals would contribute to the labour market, hampering production activities ${ }^{20}$. According to this argument, as national output depends on these labour inputs, national output- and, subsequently, national income- would fall. Similarly, decreased productivity can result in an increase in the cost of productivity, and, as a result, the prices of goods and services could rise, which could then decrease the total Gross Domestic Product (GDP). With a reduction in the demand for goods and services, producers will reduce the use of labour inputs, causing unemployment and reducing household income and overall economic growth. In this context, stewardship, innovation and access- a delicate balance of conflicting goals- has been identified. Stewardship to maintain the effectiveness of new and existing antimicrobials is essential. It is important to consider that innovation needs to be accessible, as innovation without conservation is wasteful. However, increased access without conservation and innovation would accelerate 


\section{Flow diagram of the problems and consequences associated with AMR}

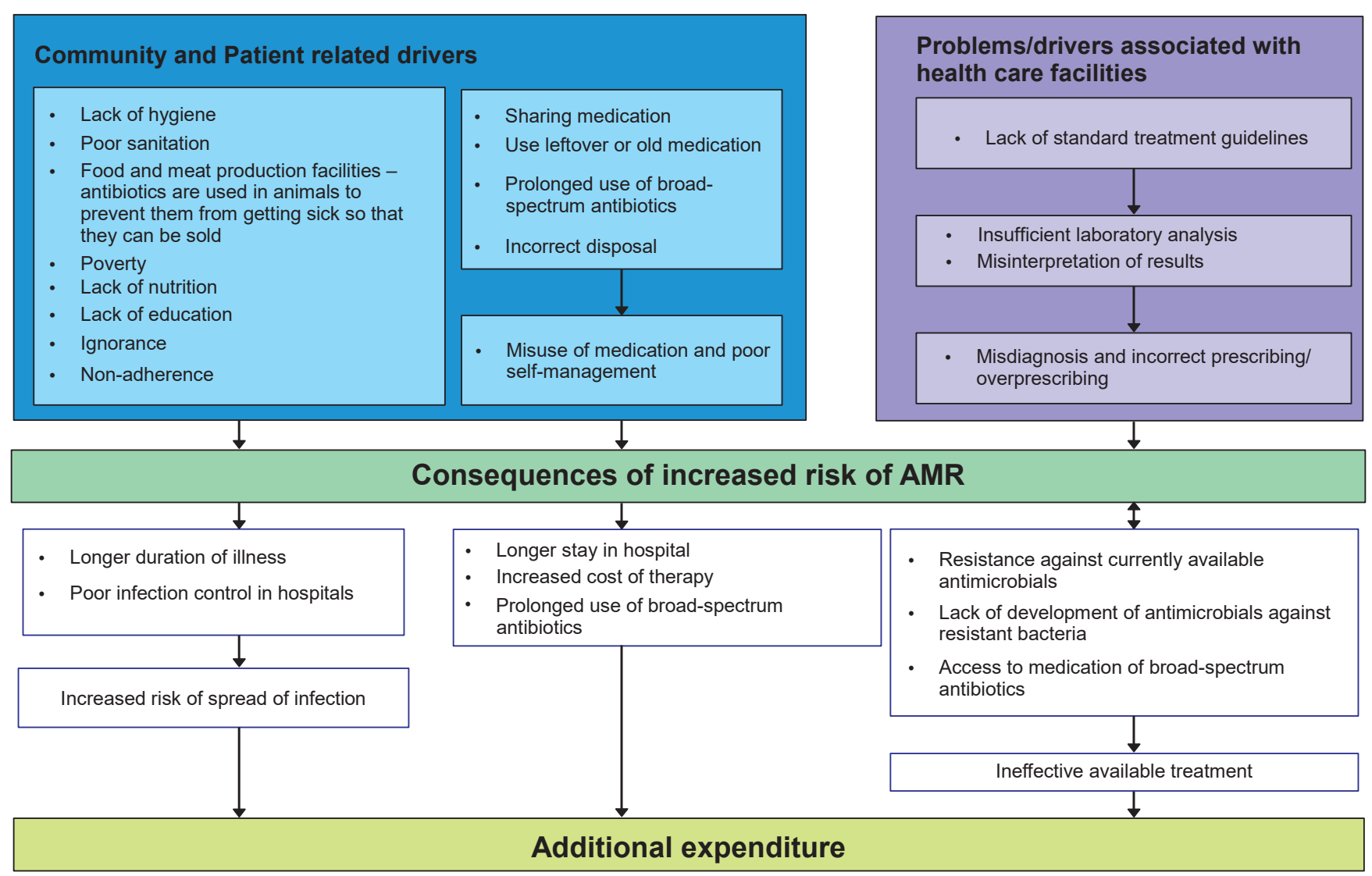

Figure 1. Drivers and consequences of antimicrobial resistance ${ }^{22}$

resistance ${ }^{15,21}$. The drivers and consequences of AMR are depicted in Figure 1:

To fully understand the role of antimicrobials, it is necessary to also see them in their cultural and social context instead of solely focussing on their economic and political dimensions. Pharmaceuticals are not only being judged by their curative powers, but also by their symbolic, culturedependent value, carrying along the characteristics of a biomedical system in general, such as efficacy. Antimicrobials are therefore often seen as a magic-like entity that functions detached from HCPs and are available to everybody as a common good ${ }^{23}$. The confidence in antimicrobials is one of the reasons for their misuse and overuse. Not only do patients see antimicrobials as a symbol for healing, but the same applies for HCPs. The consultation and prescription itself is a ritual that stands for meeting the patients' needs and regarding the illness as legitimate ${ }^{23}$. A first step is to raise awareness and educate HCPs and patients when it comes to the proper use of antimicrobials and connected risks ${ }^{24}$.

\subsection{Economic Effects of AMR}

The burden of AMR is costly, both to society and the State, which provides health care. Society is affected by the cost, as it increases out-of-pocket expenditure when visiting private sector health care facilities, which is extremely problematic for LMICs such as South Africa ${ }^{25}$. The death toll caused by AMR is already substantial, and is estimated to increase globally. A reliable estimate of the global burden of AMR is difficult to obtain, as data is not systematically and consistently collected. However, estimates from Europe indicate that the excess mortality due to resistant bacteria in hospital infections exceeds 25,000 annually, with annual costs of at least $€ 1.5$ billion. Centre for Disease Control and Prevention (CDC) has estimated that approximately $50 \%$ of antibiotics are still prescribed unnecessarily in the U.S. at a yearly cost of $\$ 1.1$ billion ${ }^{26}$. Outpatient data from U.S. indicates more than 63,000 deaths $^{27}$. The CDC calculated that, in 2013, 
over 23,000 deaths were directly attributed to AMR in the U.S ${ }^{28}$. Globally, a conservative estimate suggests that the death toll caused by AMR may be in the range of 700,000 people every year ${ }^{22}$. If this trend continues, and appropriate national and regional policies are not put in place, the health burden caused by AMR is bound to reach massive proportions. The U.K. review on $\mathrm{AMR}^{22}$ calculated that if current rates of resistance increased by $40 \%$, we could expect an average of 10 million deaths per year between 2015 and 2050. Only 0.7 million of these additional deaths would occur in North America or Europe, with the largest numbers in Africa and Asia. Estimated AMR death toll in 2050 is shown in Table 1 below.

Table 1. Statistics of the AMR Death Toll by $2050^{22}$

\begin{tabular}{|l|l|}
\hline Country & Death Toll by 2050 \\
\hline Africa & $4,150,000$ \\
\hline Asia & $2,730,000$ \\
\hline Latin America & 392,000 \\
\hline Europe & 390,000 \\
\hline North America & 317,000 \\
\hline Oceania & 22,000 \\
\hline
\end{tabular}

The detrimental health effects of AMR include negative consequences for the budget of health systems and, more broadly, the country's economy. From micro- to macro-levels, AMR has a direct negative impact on many dimensions. Firstly, requiring more intensive therapies, AMR increases health expenditures. Those are not only caused by AMR itself, but also through the consequences of antimicrobials for the immune system. Once weakened, atopic diseases can occur, such as allergies, skin diseases or bowel disorders, that easily take a chronic course and therefore generate high health expenses ${ }^{29}$. Secondly, patients and their families undergo additional non-health care related expenditures (e.g. travel time and expenditure) or suffer from income loss due to ill-health. At the societal level, AMR negatively impacts on labour market outcomes due to increased absence from work, which negatively affects the broader economic performances of countries. Additional health care costs due to AMR are driven by different factors, mainly related to inadequate or delayed start of effective AMTs, and to the increased degree of severity of infections caused by AMRs. Reviews ${ }^{30-34}$ suggest that, compared to an antibiotic-susceptible infection, an antibiotic-resistant infection is responsible for about $\$ 10,000$ to $\$ 40,000$ additional health care costs ${ }^{19}$.

The main drivers underlying additional expenditures are:
- Use of a more aggressive and expensive AMT, based on either second-line AMTs or combinations of different AMTs, or a series of tests with different treatment options before identifying the most effective strategy;

- Additional investigations, for example, advanced laboratory tests to determine the most effective therapy for that specific agent, or imaging to monitor the development of complications associated with the infection;

- More intensive forms of treatments, such as hospitalization in the case of community-acquired AMR or, if the patient develops the disease while hospitalized, transfer to intensive care units and isolation rooms;

- More intensive medical procedures, as AMR can cause an increased likelihood of undergoing surgery among patients infected with resistant organisms. Surgery may range from debridement of infected tissue to amputation $^{35}$;

- Excess length of hospital stays or treatment until the infection is eradicated. This entails additional medical and nursing care (and consequently, time) as well as use of other additional hospital resources;

- Changes in physicians' prescribing habits, as they may start prescribing second-line antibiotics to patients with first-line antibiotic susceptible infections, if the prevalence of AMR is perceived as increasing ${ }^{36}$.

Increasing rates of AMR are likely to have negative effects in other areas of the economy that, so far, have remained unexplored. Experts recognize that, in future, AMR may end up following patterns like those of epidemic outbreaks developing into pandemics ${ }^{37}$. Studies focusing on the effect of pandemic outbreaks have concluded that the areas of travelling and leisure, trade and agriculture, and finance and banking, may all experience substantial losses ${ }^{38}$. This paper highlights the drivers and consequences of AMR in LMICs, particularly using the unique challenges of AMR in South Africa, and argues for an increased focus on leadership and drives towards task shifting and the efficient utilisation of Community Health Workers (CHWs) in addressing local challenges. An aspect of the paper also highlights the key challenge in motivating CHWs to take on additional roles in health promotion as part of task shifting for AMR, especially if they are not remunerated adequately, and when it is seen to be the work of someone else. 


\subsection{WHO's Responses and Leadership}

AMR requires multifaceted policy interventions. Global efforts to tackle the negative effects of AMR on human health are coordinated by the World Health Organisation (WHO), which recently published the Global Action Strategy to tackle $\mathrm{AMR}^{12}$. WHO has also joined forces with other United Nation (UN) agencies, notably the Food and Agriculture Organisation (FAO) and World Organisation for Animal Health (OIE), to better coordinate global activities to address health risks ${ }^{39}$. The Global Health Security Agenda (GHSA) was launched in 2014 with the aim of advancing a world safe and secure from infectious disease threats. The GHSA steering group is currently chaired by Finland, with further country representation by Canada, Chile, India, Indonesia, Italy, Kenya, the Kingdom of Saudi Arabia, the Republic of Korea, and the U.S. Key efforts surrounding AMR include commitments (stemming from the 2014 Washington Meeting) to develop and integrate a global package of AMR activities. These focus on establishing comprehensive national plans, strengthening surveillance systems and laboratory capacities, as well as antibiotic stewardship. Implementation of action packages and reaching 2019 targets draws on the engagement of countries, government agencies, international organisations, and private stakeholders. In May 2017, the Interagency Coordination Group (including the WHO, OIE and FAO) on AMR had its first meeting, through which several international agencies are expected to come up with a holistic set of guidelines to address this issue in a comprehensive, sustainable way ${ }^{4}$.

Additionally, WHO adopted the Global Action Plan on Antimicrobial Resistance (GAP-AMR) in 2015, which focused on a comprehensive approach, meaning that actions in all relevant sectors be implemented synergistically. To tackle AMR, the Global Action Plan sets out five strategic objectives:

- To improve awareness and understanding of antimicrobial resistance;

- To strengthen knowledge through surveillance and research;

- To reduce the incidence of infection;

- To optimize the use of antimicrobial agents; and

- To develop the economic case for sustainable investment that takes account of the needs of all countries, and increases investment in new medicines, diagnostic tools, vaccines, and other interventions.
The GAP-AMR has been endorsed through resolutions by both the FAO of the $\mathrm{UN}^{40}$ and $\mathrm{OIE}^{41}$. In addition to the GAP-AMR, the World Health Assembly, in 2016, discussed options for a global development and stewardship framework on antimicrobial resistance. The purpose of such a framework would be to add value and achieve strategic objectives identified in the GAP-AMR, focusing on:

- Preservation of antimicrobial medicines through a stewardship framework covering control, distribution, and appropriate use;

- Development of new health technologies for preventing and controlling AMR; and

- Promotion of affordable access to existing and new antimicrobial medicines and diagnostic tools.

Further, AMR can also be addressed by focusing on WHO's building blocks of health systems, which include: leadership and governance; financing; service delivery; health workforce; medical products and technology; and information and evidence ${ }^{42,43}$. A taxonomy of health system arrangements provides additional categorisation, distinguishing between governance arrangements (political, economic, and administrative authority in the management of health systems $)^{44}$, financial arrangements (funding and incentive systems, as well as financing), delivery arrangements (human resources for health, as well as service delivery), and interventions (programmes, services, and technologies) ${ }^{45}$. Most descriptions of health system elements omit the implementation strategies to support the use of correct cost-effective interventions $s^{46,47}$.

While WHO's building blocks of health systems are considered, leadership takes on a central focus here, offering a fresh perspective on the leadership required in addressing these unique challenges, particularly that of motivation in relation to task shifting, which may be perceived as unfair ${ }^{48}$ or unjust ${ }^{49}$ if not accompanied by an increase in remuneration. Leaders need to provide support in the form of promoting need satisfaction and intrinsic work motivation, rather than monetary rewards $s^{50}$. One of the key issues argued by Gagni and Deci ${ }^{51}$ in Self Determination Theory is that a simple segregation of intrinsic and extrinsic motivating factors does not allow the full use of Cognitive Evaluation theory to explain how performance and satisfaction of personnel could be improved in workplaces. When a theory of work motivation is expanded comprehensively to address Self Determination Theory, it highlights the importance of autonomy as a 
motivational mechanism. Leaders can cultivate a work climate that supports autonomy, by for example, showing empathy towards the perspectives of CHWs, keeping them informed, encouraging them to take initiative; and thereby achieve intrinsic motivation and self-regulation.

While responding to the questions of 'How can leadership in the CHWs sector inspire the local community to WANT to make this impact?' or 'How can a young, vibrant leader guide the smaller communities in South Africa to develop CHWs and make them an important part of the community?' it becomes necessary to consider why and how the extrinsic and intrinsic motivating factors could empower CHWs to take on additional roles in the face of unique challenges in South Africa. When CHWs see that the work place is empowering them by enabling an environment where they are trusted more with task shifting, it is possible to enhance their performance and satisfaction when addressing the challenges of $\mathrm{AMR}^{51}$.

\subsection{Case Study of South Africa's Unique Challenges and Responses}

The profound inequalities in access to health care professionals, with $84 \%$ of the South African population dependent on public health care facilities ${ }^{52}$, are exacerbated by the quadruple burden of diseases, increased AMR, and the epidemic increase in NCDs in the country. Also, given South Africa's high unemployment rate of $26.5 \%$, out-of-pocket expenses worsen the financial burden to households and, as a whole, exacerbate the declining economic status of the country ${ }^{53}$. Patients with financial difficulties either avoid treatment or discontinue treatment, which results in further consequences.

Poverty is heightened by the increase in cost of medication when faced with the challenge of AMR. In addition, poverty is almost always associated with a lack of nutrition, education, sanitation, etc. Furthermore, poverty and environments which lead to ill-health are often passed down from generation to generation ${ }^{54}$. Those suffering from AMR are ill for longer periods of time, which means the likelihood of spreading the infection is greater. The cost of the infection in one patient is therefore imputed to another ${ }^{55}$. This will most likely affect public health care systems, as $84 \%$ of the South African population relies on public health care ${ }^{56}$. In this case, the more infected require more treatment, but it results in a decrease of available care and facilities per individual, thus increasing out-ofpocket expenditure in the private sector.
Access to medication is also becoming a concern in South Africa, even though $8.3 \%$ of the GDP spent on health care is dedicated to public sector health care facilities ${ }^{56}$. Despite the Abuja Declaration in 2001, when the Heads of States of African Union countries pledged to devote 15\% of their budget to improving health sectors ${ }^{57}$, this has not been implemented effectively. Moreover, when compared to the mid-1990s, the current health workforce is significantly weaker in South Africa. There are fewer doctors and nurses available for the population relying on public sector health care facilities, as production of health care workforce has not kept up with the population growth ${ }^{58}$. This highlights the issue that policies and guidelines need to be amended to eliminate these short-comings. As an entirety, the deaths caused by AMR due to any of the problems mentioned in Figure 1 affect the economic and societal growth of the country by the reduction in quality and quantity of health and development.

AMR impacts the labour market, and the implications of missed work, or job loss because of illness, are additional adverse consequences. If the out-of-stock status of essential medicines, including antibiotics, continues, and access to antibiotics is affected, then most of the population could not afford medication. As a result, they skip their treatment, causing their health to deteriorate further. With declining health, they miss work, could lose their jobs, and they become more dependent on the state for their health care needs. As a response to the issue of AMR, the National AMR surveillance activities in South Africa have focused predominantly on data available from the National Antibiotic Surveillance Forum (NASF), superseded by the current South African Society for Clinical Microbiology (SASCM), in the public health care sector. The NASF (SASCM) reports data from eight microbiology laboratories affiliated to academic centres nationwide. Although this approach provides useful data, it has several limitations, for example, data is only collected from large academic centres. Since this does not profile AMR in the general population attending primary, secondary, and non-academic tertiary health care facilities, it precludes the possibility of assessing the true extent of the problem of AMR countrywide ${ }^{59}$.

\subsection{Crucial Role of Community Healthcare Workers}

Though many countries have improved their health workforce capacity, the basic threshold of 23 skilled 
HCPs per 10,000 population has not been reach in 83 countries $^{60}$. The shortage of HCPs is a global problem, but LMICs, especially South Africa, are in a worse state than most countries due to the 'brain drain'. Brain drain is the term used to refer to a problem whereby qualified professionals in LMICs move to more developed or high-income countries, for reasons such as better standard of living and quality of life, higher salaries, access to advanced technology, and more stable political conditions $^{61,62}$. A study revealed that $17 \%$ of recently qualified South African doctors plan on emigrating, and that $80 \%$ of doctors prefer working in the private sector, not just because of the pay but due to the poor working conditions in public health care facilities. Brain drain has left South Africa with only 5.113 nurses and midwifery personnel, and 0.767 physicians per 1,000 population ${ }^{63-65}$. In 2012, the Global Pharmacy Workforce Report (GPWRFIP) noted that, in the African region, there is an intense pharmacy workforce crisis, with an average of only 0.55 pharmacists per 10,000 population $^{66}$. These low numbers contribute to the challenges in health care, and lead to difficulties in addressing AMR throughout South Africa ${ }^{67}$.

In 2006, the United Nations Member States agreed to work towards achieving universal access to health, which includes prevention, treatment, care, and support ${ }^{68}$. Part of the global issue with access to health is the insufficiency of HCPs, which can further burden health care systems ${ }^{69,70}$. The disproportionate burden of diseases in LMICs, such as South Africa, when managed by short staffed health care professionals and over-stretched public health care facilities, exacerbates the lack of quality care offered to patients who are dependent on public health care facilities. In this context, the WHO GAP-AMR plan can be used to provide evidence and guidelines to execute the plan, especially in the context of short staffed public health care facilities.

To address the shortage in staff and improve primary health care, effective strategies such as enhanced leadership and task shifting may be used to help solve compounding problems. WHO defines task shifting as involving "the rational redistribution of tasks among health workforce teams. Specific tasks are moved, where appropriate, from highly qualified health workers to health workers with shorter training and fewer qualifications in order to make more efficient use of the available human resources for health"11. WHO's guidelines highlight that task shifting could be considered one of the health systems' strengthening approaches, and could result in a "safe, efficient, effective, equitable and sustainable" system when done in consultation, after an in-depth situation analysis, and with national endorsement, effectively supported by an enabling regulatory framework ${ }^{71}$.

Task shifting could expand the human resource pool and reduce the exit rate of well trained and experienced HCPs from public health service. Also, training CHWs will offset the cost and intensive time which is spent effectively in training doctors, pharmacists, and nurses ${ }^{68}$. Several countries, such as Mozambique and Zambia, have reported on the consequences of task shifting on the health care systems and its users ${ }^{72}$. In Uganda, task shifting was the backbone for the delivery of health care services; however, most health managers and policy makers did not accept this concept, as lower cadres of health care workers were incompetent, overworked, and received inadequate support and supervision ${ }^{73}$. With adequate increase in support for supervision, training, and management of CHWs, it is possible to address current AMR issues, as CHWs have the capability of improving the cost-effectiveness of health care systems ${ }^{37}$.

CHWs were initially promoted in the 1978 Alma Ata Declaration on Primary Health Care, and were integrated into many countries' health systems by following the 22 recommendations of task shifting advocated by the WHO as a response to strengthening primary health care by rejecting 'medical elitism. However, due to inappropriate top-down implementation, the CHW programmes failed and ultimately diminished during the 1980s and 1990s. In the late 1990s and early 2000s, CHWs re-emerged as a valuable health resource to address the epidemics of malaria, Tuberculosis (TB), and HIV/AIDS, and are now being used for a wide variety of health conditions ${ }^{74}$. CHWs are generally local inhabitants with limited training, who provide specific basic health and nutrition services to members of their surrounding communities. They are expected to remain in their home village or neighbourhood, and usually work part-time as health workers. Most of the time, they are volunteers or receive a salary, but are generally not civil servants or professional employees of the Ministry of Health (MOH).

Adequate quality health care to patients can be maintained, as CHWs will have to meet established standards and quality in the appropriate tasks which they will undertake ${ }^{68}$. The development of vigorous and evidencebased guidelines for $\mathrm{CHW}$ programmes will assist in the delivery of quality health care. CHWs can provide crucial primary health care delivery, further improving health and the wellbeing of households and communi- 
ties $^{75}$. One needs to bear in mind that CHWs should not replace or take on the responsibilities of qualified physicians, pharmacists or nurses, but rather lessen the weight of the demand for health care. A large part of their role is to functionally promote the good practices of healthy behaviour in their community, as they are in direct contact with their community, and are often more trusted than the HCPs, due to cultural and linguistic proximity to patients. The WHO's Task Shifting approach recommends a major reinforcement of state-sponsored $\mathrm{CHW}$ programmes $^{76}$.

Auxiliary health care workers, such as CHWs, Pharmacy Assistants (PAs), Nursing Assistants (NAs) and others, can effectively contribute to the AMR programme by preventing infections by ensuring that hands, instruments, and environments are clean, and by keeping patients' vaccinations up to date. The HCPs (doctors and nurses) could then focus on only prescribing antibiotics when they are truly needed, where possible, testing to confirm whether antibiotics (and which one) are truly indicated when there is a clinical suspicion of bacterial infection, and prescribing appropriate antibiotics at the correct dose and for the correct duration. The recent experience of many governments with large systems of Community-Based Health Workers (CBHWs) provides evidence as to why South Africa could also consider these aspects. Assessments of CHW driven systems depend to a large extent on the objectives they are expected to achieve based on the integrated curative, preventive, and promotional activities. These vary considerably, from providing simple information to rural families to reducing mortality considerably. This is possible when CHWs have had a level of primary education that enables them to read, write and do simple mathematical calculations ${ }^{77}$.

In small-scale, well-managed projects, $\mathrm{CHWs}$ are crucial team members. In other words, the potential contribution of the CHW approach has been demonstrated. It is feasible to deploy and manage villagers as health workers, as they can provide services that improve rural health services in an extremely cost-effective manner. Evidence from several LMICs shows that CHWs seemed far superior to clinic-based services in reaching the underserved population as they bridge the social and cultural gap for patients ${ }^{78}$. Evidence shows that CHWs are trained for medically orientated activities requiring technical competence as well as socially orientated activities in communities that are aligned to public awareness and health-related behaviour changes. CHWs are inhabit- ants and integral community members, who also work in social settings such as homes, community halls, religious gatherings, etc. Their soft social skills when particularly enhanced, allows local context and culture to be integrated in their educators/health promotors' tasks ${ }^{76}$.

\subsection{Opportunity with Youth Empowerment}

Investments in more $\mathrm{CHWs}$ are critical in addressing the ever-increasing burden of AMRs in South Africa. Additionally, there is an opportunity to educate, empower and groom youth leaders, from schools and universities, from townships and metropolitan cities in community health work. Young university students were critical in striking a deal with Yale University and Bristol-MyersSquibb in providing a more affordable antiretroviral medicine, stavudine, in the early $2000 \mathrm{~s}^{79}$. Globally, young people have achieved incredible things, especially in areas of health issues. Recently, young professionals in Mexico were critical in passing the soda tax bill that is critical to the rising obesity crisis in the country ${ }^{80}$. Young people have recently been able to add up to 9 medicines related to non-communicable diseases to the WHO Essential Medicines List (EML) ${ }^{81}$.

South Africa already has a proud history of youth standing up for justice, most famously seen from the celebration of Youth Day on June $16^{\text {th }}$ every year ${ }^{82}$. Enrolling and empowering youths across disciplines, geographical distributions, and levels of education to actively participate in this critical health justice issue can not only help avert bigger crises in the short term, but also be a valuable investment in this country's future.

\section{Conclusion}

This paper has highlighted the detrimental effects that the overuse and misuse of antimicrobials are having globally, especially in terms of their impact on health, the labour market and the economy. It has also reiterated the drivers of AMR in the structure and functioning of the pharmaceutical industry and illustrated how LMICs are more vulnerable, due to the shortage of health professionals. Presenting the case of South Africa in particular, it has argued that the building blocks of the WHO Global Action Plan need to be supplemented by leadership that develops and expands the country's capacity to deal with AMRs. It does so by arguing for the use of CHWs to assist in health care and health education, to reduce the burden 
on HCPs and to help improve empirical therapy to reduce AMR, further suggesting that the youth could be mobilised to fulfil this role.

This task shifting will make a positive contribution to strengthen the overall health systems. However, to achieve this requires bold leadership that is well positioned to make a positive impact in LMICs, especially in the context of South Africa's unique challenges with the quadruple burden of diseases and increasing AMR. Leaders need to recognise the potential interest and enjoyment of task shifted work for the individual, and if this work can be allocated in a non-controlling way that promotes autonomy, it could lead to the person being intrinsically motivated to undertake the task. Leadership of well supervised CHW programmes can help alleviate the AMR burden to South Africa, when that leadership provides the necessary resources, training, motivation and support, thus becoming a beacon and guide for rest of the other LMICs to follow.

\section{References}

1. Global Union for Antibiotics Research and Development (GUARD). Berlin Declaration on Antimicrobial Resistance; 2015. Available from: crossref

2. Michael CA, Dominey-Howes D and Labbate M. The antimicrobial resistance crisis: Causes, consequences, and management. Front. Public Health. 2014; 2:145. crossref

3. Centers for Disease Control and Prevention, Office of Infectious Disease Antibiotic resistance threats in the United States; 2013. Available from: crossref

4. Report of the first meeting of the interagency coordination group on antimicrobial resistance. 2017 May. Available from: crossref

5. World Health Organisation. Implementation of the Global Action Plan on Antimicrobial Resistance. WHO GAP AMR Newsletter No. 26. 2017 May. Available from: crossref

6. Llor C, Bjerrum L. Antimicrobial resistance: risk associated with antibiotic overuse and initiatives to reduce the problem. Ther Adv Drug Saf. 2014; 5(6):229-41. crossref PMid:25436105 PMCid:PMC4232501

7. Richard JF, Tor Y. Antibiotics and bacterial resistance in the 21st century. Perspect Medicin Chem. 2014; 6:25-64.

8. Gibson PC, Govender N, Lewis D A, Bamford C, Brink A, Gottberg A von et al. Human infections and antibiotic resistance. The South African Medical Journal. 2011; 101(8):567-78.

9. Powers JH. Antimicrobial drug development- the past, the present, and the future. Clin Microbiol Infect. 2004; 10(s4):23-31. crossref PMid:15522037
10. World Health Organisation. Noncommunicable diseases. WHO, Geneva; 2017. Available from: crossref

11. Roger SM, Patterson D. The role of law and governance reform in the global response to non-communicable diseases. Magnusson and Patterson Globalization and Health. 2014; 10:44. crossref PMid:24903332 PMCid:PMC4077679

12. World Health Organisation. Global action plan on antimicrobial resistance. WHO, Geneva, 2015 Sep; Available from: crossref

13. Organisation for economic co-operation and development. Antimicrobial resistance: Policy insight. OECD, France; 2016. Available from: crossref

14. Outterson K, Powers JH, Daniel GW, McClellan MB. Repairing the broken market for antibiotic innovation. Health Affairs. 2015; 34(2):277-85. crossref PMid:25646108

15. Review on antimicrobial resistance. Tackling Drug-Resistant Infections Globally: Final report and Recommendations. 2016 May. Available from: crossref

16. Chantal MM, Elias M. Stoking the antibiotic pipeline. British Medical Journal. 2010; 340:c2115. crossref PMid:20483950

17. Piddock LJV. The crisis of no new antibiotics- what is the way forward? Lancet Infect Dis. 2012; 12:249-53. crossref

18. Shallcross LJ, Davies SC. The World Health Assembly resolution on antimicrobial resistance. J Antimicrob Chemother. 2014; 69(11):2883-5. crossref PMid:25204342

19. Cecchini M, Langer J, Slawomirski L. Antimicrobial resistance in G7 countries and beyond: Economic issues, policies and options for action. 2015 Sep. Available from: crossref

20. Smith RD, Yago M, Millar M, Coast J. A macroeconomic approach to evaluating policies to contain antimicrobial resistance: A case study of methicillin-resistant Staphylococcus aureus (MRSA). Appl Health Econ Health Policy. 2006; 5(1):55-65. crossref PMid:16774293

21. World Health Organisation. Global framework for development \& stewardship to combat antimicrobial resistance. Geneva: WHO; 2017. Available from: crossref implementation/research/WHA_BackgroundPaper-AGlobal FrameworkDevelopment Stewardship-Version2.pdf?ua=1

22. Review on antimicrobial resistance. Antimicrobial resistance: Tackling a crisis for the health and wealth of nations. London: Review on AMR, Welcome Trust, HM Government; 2014.

23. Chandler CIR, Hutchinson E, Hutchison C. addressing antimicrobial resistance through social theory: An anthropologically oriented report. London School of Hygiene \& Tropical Medicine; 2016. Available from: crossref

24. Ozrech KM, Nichter M. From resilience to resistance: politicalecologicallessonsfromantibioticand pesticideresistance. Annual Review of Anthropology. 2008; 37:267-82. crossref 
25. Out of pocket payments by medical scheme members: Research and Monitoring. 2015. Available from: crossref

26. Centers for disease control and prevention. Office of infectious disease: Antibiotic resistance threats in the United States; 2013. Available from: crossref

27. World Health Organisation. The evolving threat of antimicrobial resistance Options for action. Geneva: World Health Organization; 2012. Available from: crossref

28. ECDC and EMEA. The bacterial challenge. Time to react, ECDC/EMEA Joint Technical Report. European centre for disease prevention and control. Stockholm; 2009. Available from: crossref

29. Tyrie K, Wohl D, Curry W. Effects of antibiotic exposure and immune system challenge on the development of allergic asthma. Bios. 2013; 84(1):14-20. crossref

30. Cohen B, Larson EL, Stone PW, Neidell M, Glied SA. Factors associated with variation in estimates of the cost of resistant infections. Med Care. 2010; 48(9):767-75. crossref PMid:20706168 PMCid:PMC2924922

31. Sipahi, OR. Economics of antibiotic resistance. Expert Review of Anti-Infective Therapy. 2008; 6(4):523-39. crossref PMid:18662118

32. Smith RD, Coast J. The economic burden of antimicrobial resistance: Why it is more serious than current studies suggest [Technical Report]. London: London School of Hygiene \& Tropical Medicine; 2012. Available from: crossref

33. Tansarli GS, Karageorgopoulos DE, Kapaskelis A, Falagas ME. Impact of antimicrobial multidrug resistance on inpatient care cost: An evaluation of the evidence. Expert Review of Anti-Infective Therapy. 2013; 11(3):321-31. crossref PMid:23458771

34. World Health Organisation. Antimicrobial resistance: global report on surveillance. Geneva: WHO; 2014. Available from: crossref

35. Cosgrove SE. The relationship between antimicrobial resistance and patient outcomes: Mortality, length of hospital stay, and health care costs. Clin Infect Dis. 2006; 42(2):S82-9. crossref PMid:16355321

36. McNulty CA, Lasseter GM, Charlett A, Lovering A, Howell-Jones R, Macgowan A, et al. Does laboratory antibiotic susceptibility reporting influence primary care prescribing in urinary tract infection and other infections? J Antimicrob Chemother. 2011; 66(6):1396-404. crossref PMid:21398297

37. Spellberg B, Guidos R, Gilbert D, Bradley J, Boucher HW, Scheld WM, et al. The epidemic of antibiotic-resistant infections: A call to action for the medical community from the Infectious Diseases Society of America. Clinical Infectious Diseases. 2008; 46(2):155-64. crossref PMid:18171244

38. Jonasa, Olga B. Pandemic Risk. World Bank, Washington, DC: World Bank; 2013. Available from: crossref
39. FAO. Food and Agriculture Organisation of the United Nation; 2010. Available from: crossref

40. FAO Resolution 4/2015. Available from: crossref

41. OIE Resolution No. 26; 2015. Available from: crossref

42. World Health Organisation. Monitoring the building blocks of health systems: A Handbook of indicators and their measurement strategies. Geneva: World Health Organisation; 2010. Available from: crossref

43. World Health Organisation. What is health policy and systems research and why does it matter? Geneva: Alliance for Health Policy and Systems Research; 2007. Available from: crossref

44. World Health Organisation, Europe. 9th Futures Forum on health systems governance and public participation. Denmark: WHO Regional Office, Europe; 2006.

45. Lavis JN, Ross SE, Hurley JE, et al. Examining the role of health services research in public policymaking. Milbank Q. 2002; 80:125-54. crossref PMid:11933791 PMCid:PMC2690103

46. Grol R, Grimshaw J. From best evidence to best practice: effective implementation of change in patients' care. Lancet. 2003; 362:1225-30. crossref

47. Haines A, Kuruvilla S, Borchert M. Bridging the implementation gap between knowledge and action for health. Bull World Health Organ. 2004; 82:724-31. PMid:15643791 PMCid:PMC2623035

48. Adams JS. Inequity in social change. Berkowitz L, editor. Advances in experimental social psychology New York: Academic Press; 1965. p. 267-99.

49. Cropanzano R, Greenberg J. Progress in organizational justice: Tunneling through the maze. Cooper CL, Robertson IT, editors. International Review of Industrial and Organizational Psychology. New York: Wiley; 1997. p. 317-72.

50. Olafsen AH, Halvari H, Forest J, Deci EL. Show them the money? The role of pay, managerial needs support, and justice in a self-determination theory model of intrinsic work motivation. Scandinavian journal of psychology. 2015; 56(4):447-57. crossref PMid:25810152

51. Gagné M, Deci EL. Self-determination theory and work motivation. Journal of organizational Behavior. 2005; 26(4):331-62. crossref

52. Department of Health. Minister Aaron Motsoaledi: Health Dept Budget Vote 2017/18. DOH, Republic of South Africa; 2016. Available from: crossref

53. Statistics South Africa. People. South Africa; 2011. Available from: crossref

54. World Economic Forum. The Global Economic Burden of Non-communicable Diseases. Harvard School of Public Health, World Economic Forum; 2011. Available from: crossref

55. Howard D, Cordell R, Mcgowan JE, Packard RM, Scott RD, Solomon SL. Measuring the economic costs of antimicro- 
bial resistance in hospital settings: Summary of the centers for disease control and prevention-emory workshop. Clin Infect Dis. 2001; 33(9):1573-8. crossref PMid:11577379

56. Health Department of National Health Insurance in South Africa Policy Paper; 2011. Available from: crossref

57. World Health Organisation. The Abuja Declaration: Ten years on. Geneva: World Health Organisation; 2001. Available from: crossref

58. Hugo J. Health workers in South Africa not an easy option. Department of Health. Health Systems Trust. Available from: crossref

59. Winters C, Gelband H. The Global Antibiotic Resistance Partnership (GARP). South African Medical Journal. 2011; 101(8):556-7. PMid:21920132

60. World Health Organisation. Media centre: Global health workforce shortage to reach 12.9 million in coming decades. Geneva: WHO; 2013. Available from: crossref

61. Dodani S, LaPorte RE. Brain drain from developing countries: how can brain drain be converted into wisdom gain?. J R Soc Med. 2005; 98(11):487-491. crossref PMid:16260795 PMCid:PMC1275994

62. World Health Organisation. International Migration of Health Workers. Improving international co-operation to address the Global Health Workforce Crisis. France: OECD; 2010. Available from: crossref

63. World Health Organization. Global Health Observatory. Geneva: WHO; 2017. Available from: crossref

64. World Health Organization. Global Health Observatory. Geneva: WHO; 2017. Available from: crossref

65. World Health Organization. Global Health Observatory. Geneva: WHO; 2017. Available from: crossref

66. International Pharmaceutical Federation. 2012 FIP global Pharmacy: Work force report. FIP. The Netherlands; 2012. Available from: crossref

67. Health System Trust. South Africas chronic shortage of health care professionals. Available from: crossref

68. World Health Organisation. HIV/AIDS Programme. Taking stock: Health worker shortages and the response to AIDS. Geneva: WHO; Available from: crossref

69. Tsolekile LP, Abrahams-Gessel S, Puoane T. healthcare professional shortage and task-shifting to prevent cardiovascular disease: Implications for low- and middle-income Countries. Curr Cardiol Rep. 2015; 17(12):115. crossref PMid:26482758

70. Bertino JS. Cost burden of viral respiratory infections: issues for formulary decision makers. Am J Med. 2002; 112(6):42-9. crossref
71. World Health Organisation. Treat, Train and Retain: HIV/AIDS; Task Shifting: Global Recommendations and Guidelines. Geneva: WHO; 2008. crossref

72. Ferrinho P, Sidat. M, Goma F, Dussault G. Task-shifting: Experiences and opinions of health workers in Mozambique and Zambia. Human Resources for Health. 2012; 10:34. crossref PMid:22985229 PMCid:PMC3515799

73. Baine SO, Kasangaki A. A scoping study on task shifting: The case of Uganda. BMC Health Services Research. 2014; 14:184. crossref PMid:24754917 PMCid:PMC4036592

74. Berman PA, Gwatkin DR, Burger SE. Community-based health workers: head start or false start towards health for all? Soc Sci Med. 1987; 25(5):443-59. crossref

75. Gilmore B, Adams B J, Bartoloni A, Alhaydar B, McAuliffe $\mathrm{E}$, Raven $\mathrm{J}$, et al. Improving the performance of community health workers in humanitarian emergencies: A realist evaluation protocol for the PIECES programme. BMJ Open. 2016; 6:e011753. crossref PMid:27531730 PMCid:PMC5013374

76. CampbellC,ScottK.RetreatfromAlmaAta?'TheWHO'sreport on task shifting to community health workers for AIDS care in poor countries. Global Public Health. 2011; 6(2):125-38. crossref PMid:19916089

77. World Health Organisation. Community health workers: What do we know about them? The state of the evidence on programmes, activities, costs and impact on health outcomes of using community health workers. Geneva: WHO; 2007. Available from: crossref

78. World Health Organisation. Global Experience of Community Health Workers for Delivery of Health Related Millennium Development Goals: A Systematic Review, Country Case Studies, and Recommendations for Integration into National Health Systems, Geneva: WHO; 2010. Available from: crossref

79. Chokshi DA. Improving access to medicines in poor countries: The role of universities. PLoSMed.2006;3(6):e136. crossref PMid:16608382 PMCid:PMC1435781

80. Ahuja R. Unlocking the floodgates: A novel strategy to passsodataxes. YoungProfessionalsChronicDiseaseNetwork (YP-CDN); 2016. Available from: crossref

81. Jarvis JD, Obscherning E, Siegel K, Kishore SP. A global social network to catalyze solutions for chronic NCD a case study on the young professionals chronic disease network. Global Heart. 2016; 11(4):463-5. crossref PMid:27938843

82. South African Government. Youth Day. Republic of South Africa, 2016 Jun; Available from: crossref 